\title{
Ecological Risk Evaluation of Heavy Metal Pollution in Soil Based on Simulation
}

\author{
Yingjun Sun ${ }^{1,2 *}$ \\ ${ }^{1}$ College of Surveying and Geo-Informatics, Shandong Jianzhu University, Jinan 250014, China \\ ${ }^{2}$ College of Geomatics, Shandong University of Science and Technology, Qingdao 266510, China
}

Received:15 August 2016

Accepted: 8 February 2017

\begin{abstract}
Heavy metals pollution of surface soils is a major global issue. To assess the ecological risk caused by heavy metals, 280 samples were collected in Chiping, Shandong Province, China. Eight different heavy metals in surface soils $(\mathrm{Cu}, \mathrm{Pb}, \mathrm{Cd}, \mathrm{Cr}, \mathrm{Hg}, \mathrm{Ni}, \mathrm{Zn}$, and $\mathrm{As})$ were analyzed in this study. The author got the realization of the eight kinds of heavy metals respectively based on sequential simulation methods. Next, the ecological risk of the region of heavy metals was assessed using the Hakanson potential danger index. The result showed that $\mathrm{Hg}$ was the main heavy metal problem in ChiPing. The potential ecological risk caused by $\mathrm{Hg}$ amounts to 200 on the Hakanson potential danger index, which was classified as 'high.' $\mathrm{Cd}$ has a potential ecological risk of nearly 72 , which was classified as 'medium.' The comprehensive potential ecological risk caused by all eight different heavy metals was 278.34 . Therefore, the heavy metal pollution of the study area was associated with a 'medium' potential ecological risk. Finally, the result was analyzed based on the land use map. We found that the highest integrated potential ecological risk area was located in plough land.
\end{abstract}

Keywords: ecological risk assessment, heavy metal, pollution, spatial variability, soil, simulation

\section{Introduction}

Air, water, and soil are the most important components of the living environment for human beings. In recent years, with the quick development of urbanization and industrialization, the contamination of soil by heavy metals has become an increasing public concern [1-4]. The pollution caused by heavy metals in agricultural soil can affect food quality and safety. To date, various potentially toxic elements (PTEs) have been identified, such as arsenic (As), chromium $(\mathrm{Cr})$, copper $(\mathrm{Cu})$, nickel $(\mathrm{Ni})$, lead $(\mathrm{Pb})$, and zinc $(\mathrm{Zn})$, which are known to influence human

*e-mail: sdjzusyj@126.com disease by their respective deficiency or toxicity [5]. Heavy metal contaminants in the soil can enter the human body through various means. Highly toxic heavy metals may result in serious ecological risks [6]. It is necessary to monitor heavy metal contamination in the soil, access the potential ecological risk of heavy metals, and then take remediation measures on affected soil. Such approaches have been described by such publications as the "Guide to Strengthening Food Safety from the Health and Family Planning Commission," "Opinions on Deepening Rural Reform," and "Acceleration of the Modernization of Agriculture" by the State Council of China [7].

Many studies have been carried out regarding heavy metal pollution. The usual method is to collect soil samples, extract the various heavy metals, and then assess 
the soil pollution and potential ecological risk [8-15]. Most of the research was based on the samples directly. However, the number of sample points is often limited in terms of representing the real status of the entire study area. To address this problem, the paper made use of the Geostatistics method to simulate the attributes of heavy metals at unsampled points. Then the assessment was carried out based on the 1,000 given realizations of the whole area.

Geostatistics has been widely used in the field of soil science [16-17]. Goovaert [18] summarized the application of Geostatistics in soil science, including the description of spatial patterns, quantitative modeling of spatial continuity, spatial prediction, and uncertainty assessment. In this paper, the author made use of the 'bin' variogram to quantify the spatial distribution of heavy metal concentrations, and the 'simulated' map to represent the different pollution status of heavy metals in the study area. It is well known that there are two different methods in Geostatistics: Kriging and simulation. Kriging methods tend to get more 'accurate' and 'smoothed' values of the unsampled points. The results are based on the condition of the minimum local error variance [19]. However, methods of simulation pay more attention to the detailed spatial pattern of the sampled points. They reproduce the statistics drawn from sampled points, such as the histogram or the semivariogram model [20]. Thus the maximum and the minimum value will be reserved in the map, which is very important for the discovery of the pollution sources. The paper selected the sequence Guassian simulation method to realize the spatial prediction of heavy metal pollution in Chiping, China. In a future study, the uncertainty of risk assessment can be accessed based on the uncertainties in the spatial distribution of attribute values, and government may take different remediation scenarios according to the level of probability.

\section{Materials and Methods}

\section{Sampling and Analysis}

Chiping is located west of Shandong Province, China. It covers an area of $1,003.37 \mathrm{~km}^{2}$ and has 542,000 inhabitants. It is an important cotton growth region both in the province and in China. The paper designed $2 \times 2 \mathrm{~km}$ uniform grids for sampling across the whole study area. 280 topsoil samples $(0-20 \mathrm{~cm})$ were collected from each grid center. The central point position was recorded using GPS. Fig. 1 shows the locations of sample sites. Approximately $1 \mathrm{~kg}$ of soil sample was collected at each location using a stainless steel spade and stored in selfsealing plastic bags.

Soil samples were air-dried, ground, and a $2 \mathrm{~mm}$ nylon sieve was used to remove rough materials and other debris. Each digested sample was analyzed by inductively coupled plasma atomic absorption spectrometry (ICP/AES) for the following heavy metals: $\mathrm{As}, \mathrm{Cd}, \mathrm{Cr}, \mathrm{Cu}$, $\mathrm{Hg}, \mathrm{Ni}, \mathrm{Pb}$, and $\mathrm{Zn}$. All the crushed and dried samples were introduced into a plasma (at a temperature in the order of $6,000-10,000 \mathrm{k}$ ). The elements were converted to gaseous atoms (then ions). A spectrometer was used to separate the different light emitted by different elements [21]. Quality assurance and quality control was made based on standard reference materials obtained from the Center of National Standard Reference Materials of China [22]. One blank and one standard sample were inserted with every 10 samples. The relative standard deviations were all less than $10 \%$. All samples were analyzed in duplicate. When the relative standard deviation was within $5 \%$, the results were accepted. The results met the accuracy demand of the Technical Specification for Soil Environmental Monitoring HJ/T 166-2004 [23].

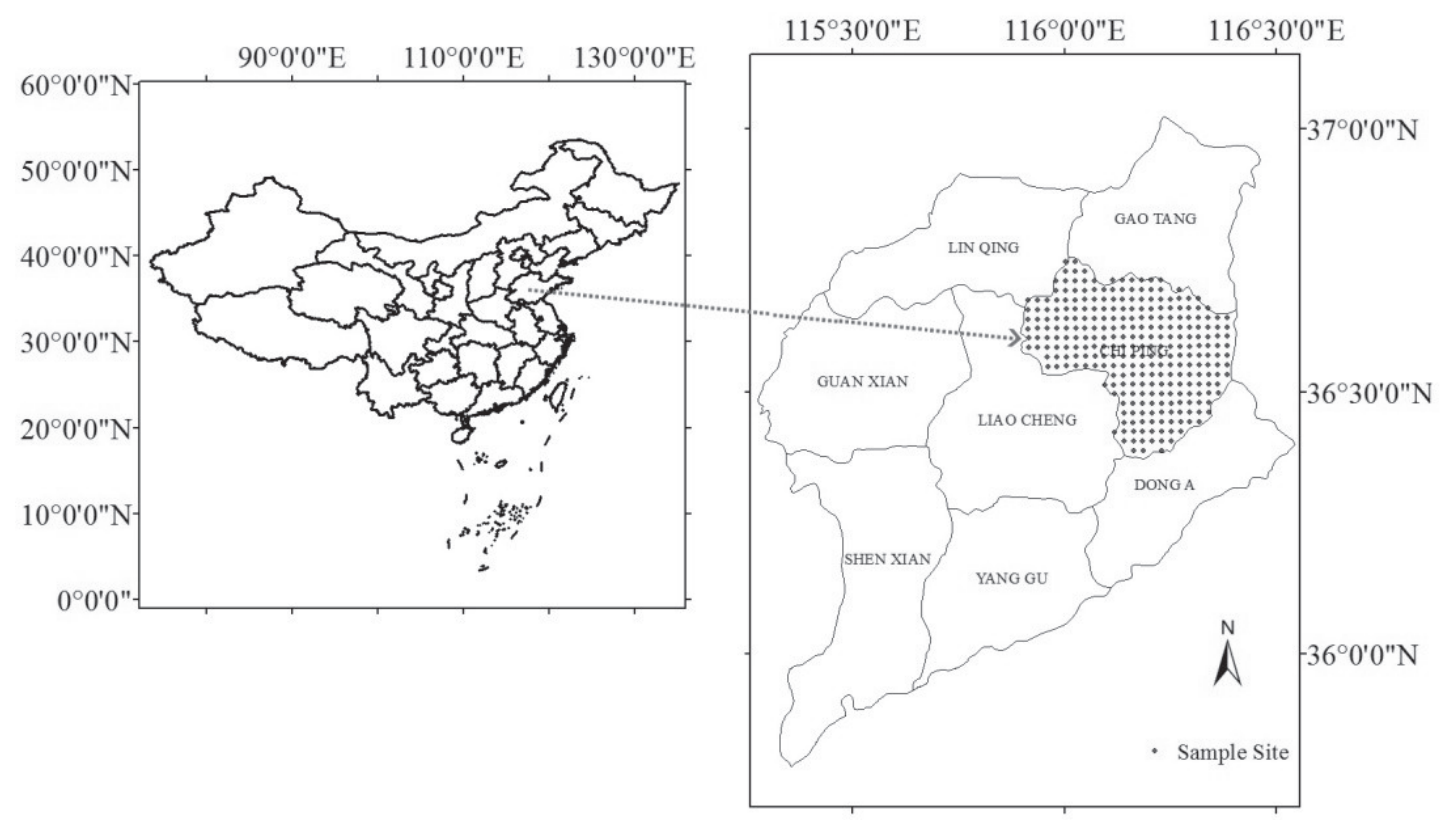

Fig. 1. Study area. 


\section{Data Processing}

Sample data was processed using geostatistical methods. First was testing the distribution of all the heavy metals with a histogram. Then, semivariogram model selections and model cross-validation were carried out. The main parameters in theoretical models included nugget $\left(\mathrm{C}_{0}\right)$, sill $\left(\mathrm{C}_{0}+\mathrm{C}\right)$, range (Range), nug/sill ratios $\left(\mathrm{C}_{0} /\left(\mathrm{C}_{0}+\mathrm{C}\right)\right)$, and coefficient of determination $\left(\mathrm{R}^{2}\right)$. The nug/sill ratios are often used for spatial heterogeneity and reflect the influence of regional factors (nature) and the role of non-regional factors (human factors). Soil is generally contaminated by heavy metals from two main sources: natural factors such as weathering, erosion of parent rocks, atmospheric deposition and volcanic activities; and anthropogenic activities such as sewage irrigation, addition of manures, fertilizers, and pesticides [24-27]. When $\mathrm{C}_{0} /\left(\mathrm{C}_{0}+\mathrm{C}\right)<0.25$, the variable space mutation gave priority to the structural variation (nature), and the variables have a strong spatial correlation. When , the variables have a moderate spatial correlation. When , the variables are random and the variables of spatial correlation are very weak. Finally, GS+ (v.9) software was used to perform the geostatistical analysis of the data. Sequential Gaussian simulation method was used to estimate the unobserved points.

\section{Assessment Method}

The potential ecological risk of heavy metals in soil can be accessed by a potential ecological risk index [28]. Based on concentrations of heavy metals and ecological factors, the method can provide a quantitative result. The equations to compute the potential ecological risk of each heavy metal and the integrated potential ecological risk are as follows:

$$
\begin{gathered}
E_{r}^{i}=T_{r}^{i} \times C_{f}^{i} \\
I R \\
\sum_{i=1}^{N} E_{r}^{i}=\sum_{i=1}^{N} T_{r}^{i} \times C_{f}^{i}
\end{gathered}
$$

...where $T_{r}^{i}$ is the toxic response factor of different heavy metals; the corresponding values of $\mathrm{Hg}, \mathrm{Cd}$, $\mathrm{As}, \mathrm{Pb}, \mathrm{Ni}, \mathrm{Cu}, \mathrm{Cr}$, and $\mathrm{Zn}$ are $40,30,10,5,5,5$, 2, $1 ; C_{f}^{i}=C_{i} / C_{r}^{i}$ is the pollution coefficient of each heavy metal; $C_{i}$ is the concentration of each heavy metal; and $C_{r}^{i}$ is the recommended value of heavy metal concentration in soils [29]. The paper selected the recommended values for Shandong Province (Table 1) [30]. The presence of various different heavy metals would result in a higher comprehensive potential ecological risk. The classifications defined by Hakanson are listed in Table 2.

The result of total potential ecological risk was analyzed in ArcGIS. When overlaid with the land use map in the study area, we can roughly identify the source of heavy metal pollution.
Table 1. Commended values of heavy metal concentrations in soil $(\mathrm{mg} / \mathrm{kg})$.

\begin{tabular}{|c|c|c|c|}
\hline Element & $\begin{array}{c}\text { Background } \\
\text { values } \\
\text { of Shandong }\end{array}$ & $\begin{array}{c}\text { Background } \\
\text { values } \\
\text { of China }\end{array}$ & $\begin{array}{c}\text { Global soil } \\
\text { median }\end{array}$ \\
\hline $\mathrm{Cu}$ & 24.0 & 22.6 & 30 \\
\hline $\mathrm{Zn}$ & 63.5 & 74.2 & 90.0 \\
\hline $\mathrm{Pb}$ & 25.8 & 26.0 & 35.0 \\
\hline $\mathrm{Cd}$ & 0.084 & 0.097 & 0.350 \\
\hline $\mathrm{Cr}$ & 66.0 & 61.0 & 70.0 \\
\hline $\mathrm{Ni}$ & 25.8 & 26.9 & 50.0 \\
\hline $\mathrm{Hg}$ & 0.019 & 0.065 & 0.060 \\
\hline $\mathrm{As}$ & 9.3 & 11.2 & 6.00 \\
\hline
\end{tabular}

Table 2. Classification of potential ecology risk by Hakanson.

\begin{tabular}{|c|c|c|c|c|c|}
\hline \multicolumn{6}{|c|}{ Potential ecological risk } \\
\hline & Slight & Medium & High & Higher & Highest \\
\hline $\mathrm{E}_{\mathrm{r}}^{\mathrm{i}}$ & $<40$ & $40-80$ & $80-160$ & $160-320$ & $>320$ \\
\hline IR & $<50$ & $150-300$ & \multicolumn{2}{|c|}{$300-600$} & $\geq 600$ \\
\hline
\end{tabular}

\section{Results and Discussion}

\section{Explore Data Analysis}

To make use of the simulation method, the prerequisite is that the spatial data distribution satisfied the assumption of multivariate normality. The histograms of each heavy metal were used to test the distribution of heavy metals. $\mathrm{Cd}, \mathrm{Cr}, \mathrm{Ni}$, and $\mathrm{Pb}$ had almost normal distributions, with low skewness and kurtosis values close to 3 . The other four heavy metals values were log transformed to satisfy requirements for normal distribution.

Four theoretical models were used to fit the semivariance function models: the exponential model, the Gaussian model, the spherical model, and the linear model (Fig. 2). The fitted results of the soil heavy metal semivariance function (Table 3) show that the nug/ sill ratios $\mathrm{C}_{0} /\left(\mathrm{C}_{0}+\mathrm{C}\right)$ of $\mathrm{As}$ and $\mathrm{Hg}$ were smaller than 0.25 . This suggested that the spatial variation of the two elements mainly arises from the soil parent materials, topography, and other structural variations. This result also shows that the nug/sill ratios of $\mathrm{Cd}, \mathrm{Cr}, \mathrm{Ni}, \mathrm{Zn}, \mathrm{Pb}$, and $\mathrm{Cu}$ were between 0.25 and 0.75 , indicating a medium spatial correlation. In the analysis of semivariance, we found that the sampling schedule was very important. The uniform 2 $\mathrm{km}$ grid sampling was limited to provide information of short-distance spatial variation. For example the nugget of $\mathrm{Hg}$ is forced to zero in Fig. 2, where this was not backed up by the data. 
CP-As-Variogram

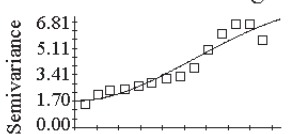

$0.00 \quad 18638.67 \quad 37277.3555916 .02$

Separation Distance $(\mathrm{h})$

CP-Cr-Variogram

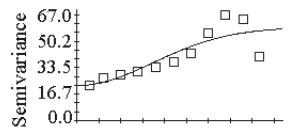

$0.0018638 .67 \quad 37277.35 \quad 55916.02$

Separation Distance $(\mathrm{h})$

CP-Hg-Variogram

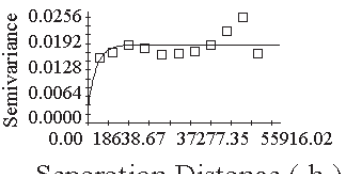

Separation Distance ( h )

CP-Pb-Variogram

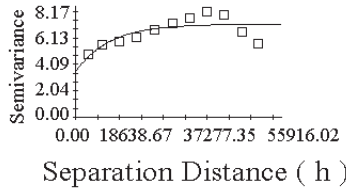

CP-Cd-Variogram

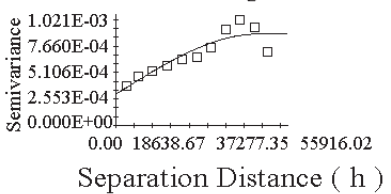

CP-Cu-Variogram

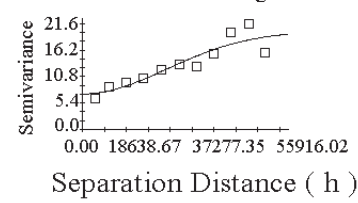

CP-Ni-Variogram

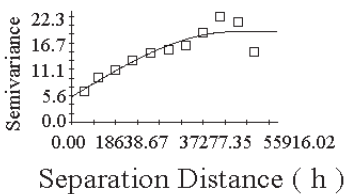

CP-Zn-Variogram

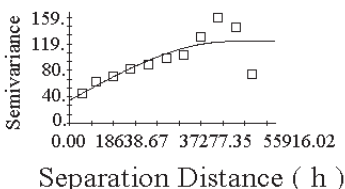

Separation Distance $(\mathrm{h})$

Fig. 2. Semivariogram of heavy metal in Chiping.

Table 3. Semivariograms fitting of heavy metals in soils from Chiping.

\begin{tabular}{|c|c|c|c|c|c|}
\hline & Model & $\mathrm{C}_{0}$ & Sill & Range & $\begin{array}{c}\mathrm{C}_{0} / \\
\left(\mathrm{C}_{0}+\mathrm{C}\right)\end{array}$ \\
\hline $\mathrm{As}$ & Gaussian & 1.73 & 8.469 & 81,752 & 0.204274 \\
\hline $\mathrm{Cd}$ & Spherical & 0.000302 & 0.000884 & 48,500 & 0.341629 \\
\hline $\mathrm{Cr}$ & Gaussian & 22.2 & 59.03 & 53,000 & 0.37608 \\
\hline $\mathrm{Ni}$ & Spherical & 5.37 & 19.07 & 45,800 & 0.281594 \\
\hline $\mathrm{Pb}$ & Exponential & 3.52 & 7.202 & 28,800 & 0.488753 \\
\hline $\mathrm{Zn}$ & Spherical & 34.5 & 123.1 & 45,500 & 0.28026 \\
\hline $\mathrm{Cu}$ & Gaussian & 7.26 & 20.13 & 58,370 & 0.360656 \\
\hline $\mathrm{Hg}$ & Exponential & 0.00344 & 0.01898 & 7,500 & 0.181243 \\
\hline
\end{tabular}

\section{Spatial Distribution and Probability Map of Heavy Metals}

The result spatial distributions of the eight heavy metals were based on the 1,000 realizations of simulation. The paper took the upper limit of the background value of heavy metals in soil established by the local government as the standards (Table 1). The legend of each heavy metal was set up to more than 10 intervals to extract the details of spatial distribution (Fig. 3).
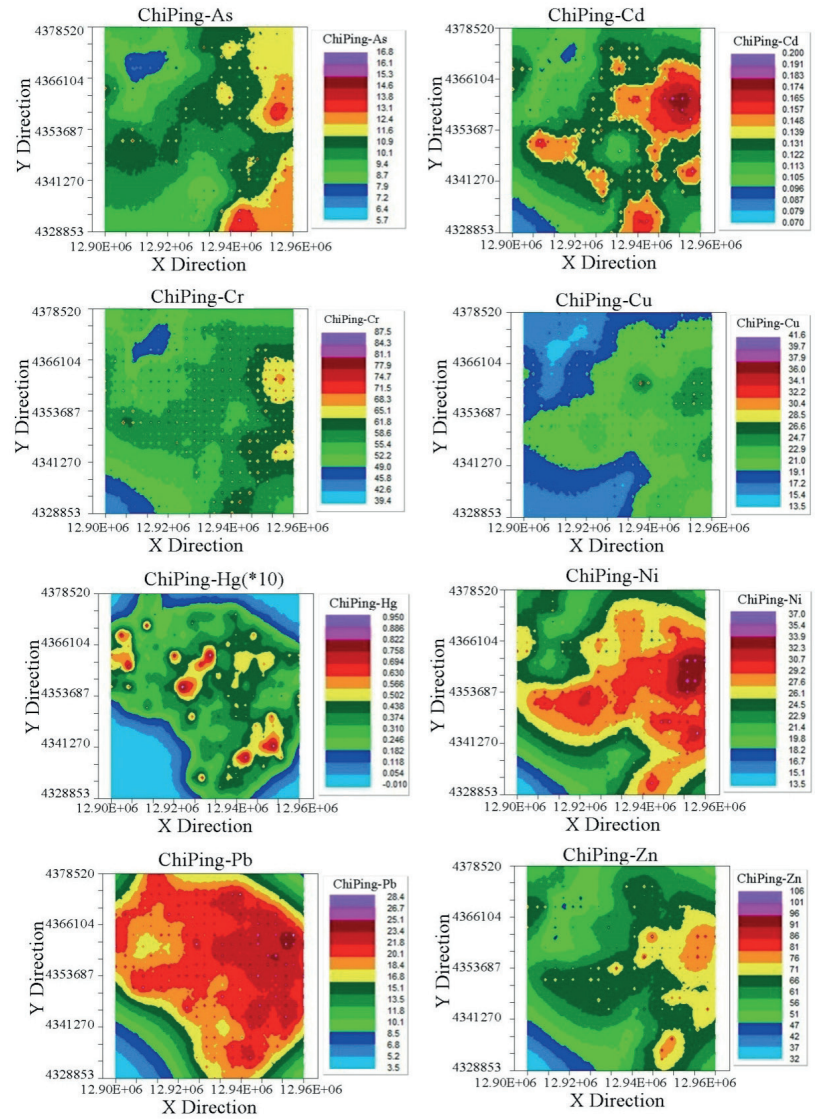

Fig. 3. Spatial distribution of heavy metal in Chiping.
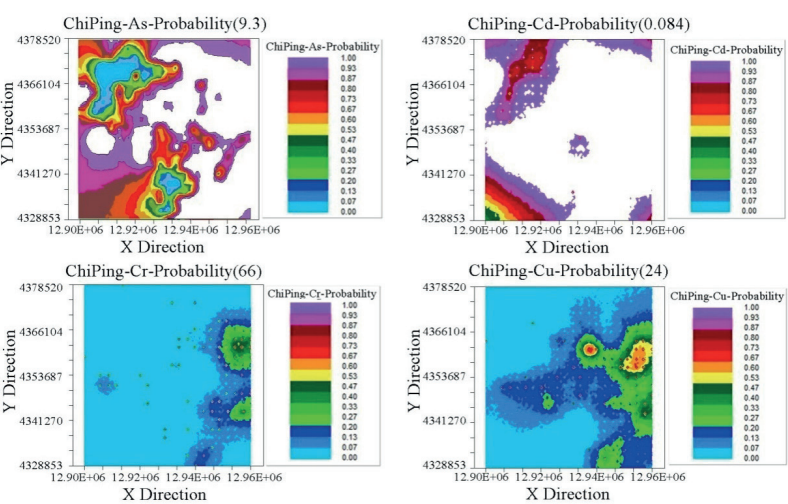

ChiPing-Cu-Probability(24)
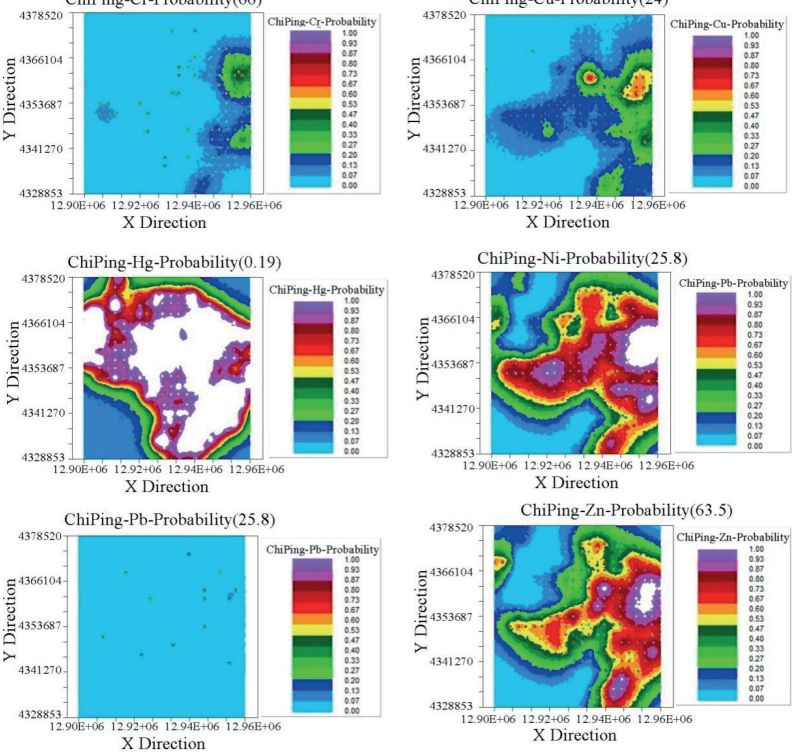

Fig. 4. Probability map of heavy metal in Chiping. 

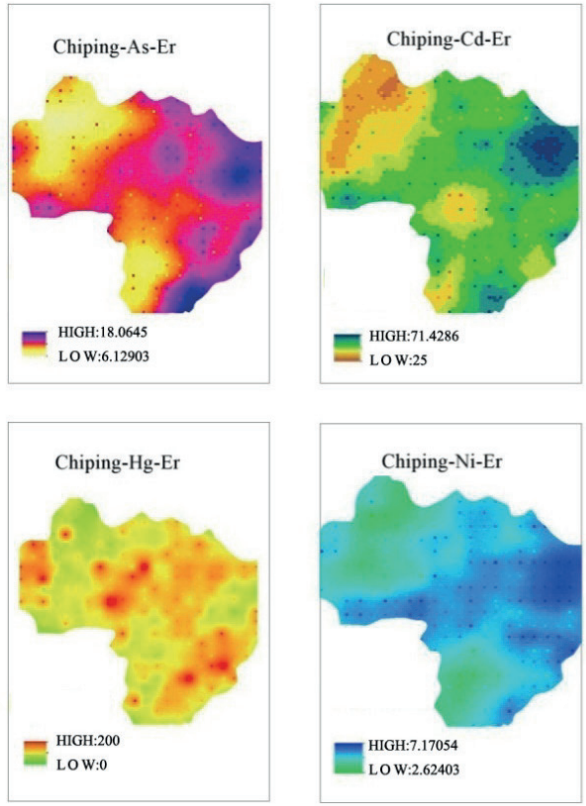
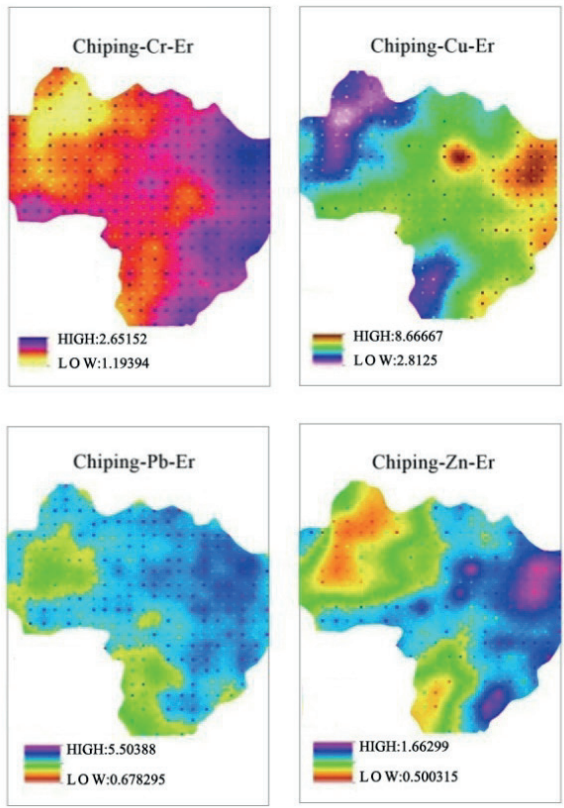

Fig. 5. Potential ecological risk of heavy metal in Chiping.

According to the spatial distribution of each heavy metal, the paper found that there were no detectable $\mathrm{Pb}$, $\mathrm{Cr}$, and $\mathrm{Cu}$ present in the simulation results. The $\mathrm{Zn}$ - and Ni-contaminated area was about one third or half of the whole area. However, $\mathrm{Cd}, \mathrm{Hg}$, and As pollution were spread widely across the whole area. High accumulation was found in the middle of the eastern and in the southern parts of the study area.

In addition, the probability map of each heavy metal was made with the corresponding background threshold values listed in Table $1 . \mathrm{Pb}, \mathrm{Cr}$, and $\mathrm{Cu}$ had little probability of exceeding the threshold value (Fig. 4). Some areas for $\mathrm{Zn}$ and $\mathrm{Ni}$ had probabilities $>50 \%$ for exceeding the threshold value. For $\mathrm{Cd}, \mathrm{Hg}$, and As, almost $80 \%$ of the total area had a probability $>90 \%$ of exceeding the threshold value. The background value is the normal value

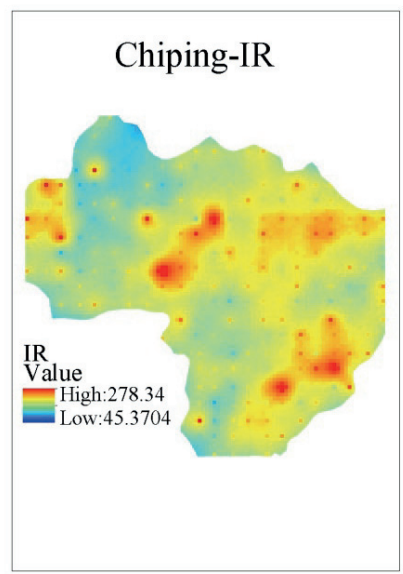

Fig. 6. Integrated potential ecological risk of heavy metal in Chiping. of each element in soil. The high probability to exceed the threshold represented the contamination of soil. These results were the same as those from the spatial distribution analysis.

A strong relationship was found between some of the heavy metals, for example $\mathrm{Cu}$ and $\mathrm{Zn}$. Including crosscorrelations in the simulation method maybe improve the precision of the results. The paper would take it as the further study content in the near future.

\section{Potential Ecological Risk of Heavy Metals}

The evaluation of the Hakanson potential ecological risk was carried out for each heavy metal. So did the comprehensive risk based on all the heavy metal-integrated contamination. The results showed that $\mathrm{Hg}$ was the main

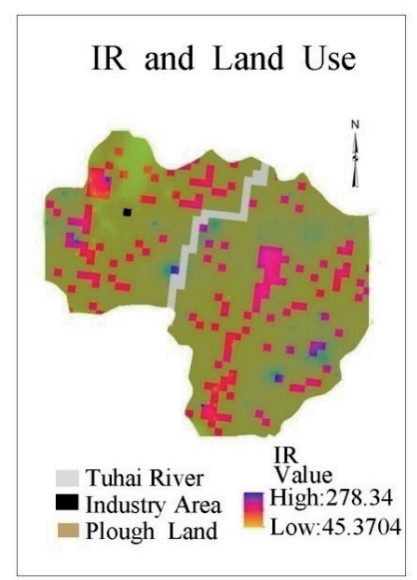

Fig. 7. Overlaid map of integrated potential ecological risk with land use map. 
heavy metal contamination problem in Chiping. The maximum potential ecological risk caused by $\mathrm{Hg}$ is 200 , which represented a 'high' classification. The maximum potential ecological risk of $\mathrm{Cd}$ contamination is nearly 72, which represented a 'medium' classification (Fig. 5). The comprehensive potential ecological risk caused by all eight examined heavy metals is 278.34 . Therefore, the heavy metal pollution across the study area is classified as 'medium' potential ecological risk (Fig. 6).

The result of integrated potential ecological risk was overlaid with the land use map of the study area (Fig. 7). As we can see, plough land is the primary land use type in the study area, amounting to $63.25 \%$ [31]. In Fig. 7, we can find that most of the highest-integrated potential ecological risk area was located in plough land. Meanwhile, two parts of them were along the Tuhai River. The distribution of the industrial area was limited in Fig. 7, which implied little effect of heavy metal contamination caused by local industry.

\section{Conclusions}

Eight different heavy metals $(\mathrm{Cu}, \mathrm{Pb}, \mathrm{Cd}, \mathrm{Cr}, \mathrm{Hg}, \mathrm{Ni}$, $\mathrm{Zn}$, and As) in surface soils were analyzed in Chiping, China. The variogram analysis showed that $\mathrm{As}$ and $\mathrm{Hg}$ had a strong spatial correlation. The variable space mutation prioritized the soil parent materials, topography, and other structural variations. The other six heavy metals were more likely to be sourced from human activities. Based on the sequential simulation methods, this paper got the different realizations of the eight different heavy metals. Next, the ecological risk of the "simulated region" of heavy metals was assessed using the Hakanson potential danger index.

The pollution of heavy metal in soil may be further transferred to underground water and plants [32]. This would be a long-term threat to human health, plant growth, and the total environment. The potential ecological risk caused by most of the heavy metals is slight, except for the main heavy metal contamination caused by Hg. As a result, the whole study area was faced with the "medium" integrated ecological risk. To analyze the source of heavy metal contamination, the paper overlaid the land use map with the integrated ecological risk map. The result showed that the highest ecological risk caused by heavy metal were scattered in plough land, along with the Tuhai River. It can be concluded that the contamination in Chiping was not caused by industry. The main pollution of heavy metal in the study area was caused by $\mathrm{Hg}$, which perhaps originated from the soil parent materials. Essential measures and remediation should be taken within these areas to prevent further deterioration.

\section{Acknowledgements}

This work was supported by the following projects:

1. The National Natural Science Foundation of China (Nos. 41301509, 41271413)
2. The China Postdoctoral Science Foundation (No. 2014M561950)

3. Qingdao municipal bureau of human resource and social security (No. 201409)

The land use map was provided by the National datasharing infrastructure of earth system science.

\section{References}

1. LU J.S., ZHANG Z.L., LIU Y., DAI J.R., WANG X., WANG M.X. Sources identification and hazardous risk delineation of heavy metals contamination in Rizhao city. Acta Geographica Sinica, 67 (7), 971, 2012.

2. GAO H.F., BAI J.H., XIAO R., LIU P.P., JIANG W., WANG J.J. Levels, sources and risk assessment of trace elements in wetland soils of a typical shallow freshwater lake China. Stoch Env Res Risk A 27 (1), 275, 2013.

3. MAAS S., SCHEIRLER R., BENSLAMA M., CRINI N., BRAHMIA Z., BENYACOUB S., GIRAUDOUX P. Spatial distribution of heavy metal concentrations in urban, suburban, and agricultural soils in a Mediterranean city of Algeria. Environmental Pollution 158, 2294, 2010.

4. QIAO X., SCHMIDT A.H., TANG Y., XU Y., ZHANG C. Demonstrating urban pollution using toxic metals of road dust and roadside soil in Chengdu, southwestern China. Stoch Env Res Risk A 28 (4), 911, 2014.

5. MCKINLEY J.M., OFTERDINGER U., YOUNG M., BARSBY A., GAVIN A. Investigating local relationships between trace elements in soils and cancer data. Spatial Statistics 5, 25, 2013.

6. KHAN M.N., WASIM A.A., SARWAR A., RASHEED M.F. Assessment of heavy metal toxicants in the roadside soil along the N-5 national highway Pakistan. Environ Monit Assess 182, 587, 2011.

7. GUAN Y., SHAO C.F., GU Q.B., JU M.T., HUANG X.J. Study of a comprehensive assessment method of the environmental quality of soil in industrial and mining gathering area. Stoch Environ Res Risk Assess 30 (1), 91, 2016.

8. SANY S.B.T., HASHIM R., REZAYI M., SALLEH A., SAFARI O. A review of strategies to monitor water and sediment quality for a sustainability assessment of marine environment. Environ. Sci. Pollut. Res. 21, 813, 2014.

9. LI R.P., HAO Y.H., LI G.D., JIANG Y.D., ZHANG H., HAN X.M. Characteristics and sources analysis of soil heavy metal pollution in Taian, China. Journal of Agro-Environment Science 30 (10), 2012, 2011.

10. WANG M., BAI Y.Y., CHEN W.P., MARKERT B., PENG C., OUYANG Z.Y. A GIS technology based potential ecorisk assessment of metals in urban soils in Beijing, China. Environmental pollution 161, 235, 2012.

11. HAMID YIMIT, ZULPIYA MAMAT, LI J.T., LI X.G. Sources explanation, pollution and assessment of potential ecological hazards of heavy metals in the soils of Yanqi basin, China. China environmental science 34 (6), 1523, 2014.

12. KEBIR TAHAR, BOUHADJER KELTOUM Effects of heavy metals in soil and plant in the industrial area, west Algeria. Journal of the Karean Chemical Society 55 (6), 1018, 2011.

13. LU S.J., WANG Y.Y., HE L.H. Ecological risk of heavy metals on the peddy soils at a village in Hunan. Environmental science \& technology 37 (12), 100, 2014. 
14. ZHANG Z.Y., JI L.L., ABUDUWAILIL, JIANG F.Q. Source identification and potential ecological hazards assessment of trace metalloid/heavy metals in the soil of Tianshan Mountains, Xinjiang, China. Ying Yong Sheng Tai Xue Bao, 25 (11), 3168, 2014

15. HAN P., WANG J.H., FENG X.Y., MA Z.H., LU A.X., WEI L., YAN L.B. Ecological risk assessment of heavy metals in soils in Shunyi, Beijing. Journal of Agro-Environment Science 34 (1), 103, 2015.

16. DELAVAR M.A., SAFARI Y. Spatial distribution of heavy metals in soils and plants in Zinc Town, northwest Iran. Int. J. Environ. Sci. Technol. 13, 297, 2016.

17. ZARE CHAHOUKI M.A., ZARE CHAHOUKI A., KHALASI AHVAZI L. Comparing Geostatistical Approaches for Mapping Soil Properties in Poshtkouh Rangelands of Yazd Province, Iran. Vegetos, 24 (1), 77, 2011.

18. GOOVAERTS P. Geotatistics in soil science: state-of-the-art and perspectives. Geodema 89, 1, 1998.

19. SUN Y.J., DING N., CAI F., MENG F. Spatial analysis of heavy metals in surface soils based on GeoStatistics. Geoinformatics 2008 and Joint Conference on GIS and Built Environment: Monitoring and Assessment of Natural Resources and Environments. International Society for Optics and Photonics, 714514, 2008.

20. GOOVAERTS P. Geostatistics for Natural Resources Evaluation, Oxford Univ. Press, New York, 125, 1997.

21. BAI J., CUI B., CHEN B., ZHANG K., DENG W., GAO H., XIAO R. Spatial distribution and ecological risk assessment of heavy metals in surface sediments from a typical plateau lake wetland, China. Ecol. Model 222, 301, 2011.

22. MENG F., DING N., SUN Y.J. Assessment of heavy metal pollution in Chinese suburban farmland. Pol. J. Environ. Stud. 23 (6), 447, 2014.

23. State Environmental Protection Administration of China (SEPAC). The Technical Specification for Soil Environmental
Monitoring HJ/T 166-2004. China Environmental Press, Beijing, 2004.

24. SHAH M.T., SHAHEEN B., KHAN S. Pedo and biogeochemical studies of mafic and ultramafic rocks in the Mingora and Kabal areas, Swat, Pakistan. Environ Earth Sci, 60, 1091, 2010.

25. SEKOMO C.B., NKURANG E., ROUSSEAU D.P., LENS P.N. Fate of heavy metals in an urban natural wetland: the Nyabugogo Swamp (Rwanda). Water Air Soil Pollut 214, 321, 2011.

26. ISLAM M.S., AHMED M.K., AL-MAMUN M.H. Metal speciation in soil and health risk due to vegetables consumption in Bangladesh. Environ Monit Assess 187, 288, 2015.

27. QU C., LI B., WU H., WANG S., LI F. Probabilistic ecological risk assessment of heavy metals in sediments from China's major aquatic bodies. Stoch Environ Res Risk Assess. 30, 271, 2015.

28. HAKANSON L. An ecological risk index for aquatic pollution control a sedimentological approach. Water Res 14, 975, 1980.

29. HAKANSON L. Aquatic contamination and ecological risk: an attempt to a conceptual framework. Water Res 18 (9), 1107, 1984

30. CNEMC (China National Environmental Monitoring Centre). The background values of Chinese soils. Environmental Science Press of China, Beijing, 329, 1990.

31. Introduction of Chiping, Available at http://www.chiping. gov.cn/, 2010.

32. NABULO G., BLACK C., CRAIGON J., YOUNG S. Does consumption of leafy vegetables grown in pen-urban agriculture pose a risk to human health? Environ. Pollut. 162, 389, 2012. 